\title{
Inadequate Nutrient Intakes in Youth of a Remote First Nation Community: Challenges and the Need for Sustainable Changes in Program and Policy
}

\author{
Allison Gates, ${ }^{1}$ Rhona M. Hanning, ${ }^{1}$ Michelle Gates, ${ }^{1}$ \\ Daniel McCarthy, ${ }^{2}$ and Leonard J. S. Tsuji ${ }^{1,2}$ \\ ${ }^{1}$ School of Public Health and Health Systems, Faculty of Applied Health Sciences, University of Waterloo, 200 University Avenue West, \\ Waterloo, ON, Canada N2L $3 G 1$ \\ ${ }^{2}$ Environment and Resource Studies, Faculty of Environment, University of Waterloo, 200 University Avenue West, \\ Waterloo, ON, Canada N2L $3 G 1$
}

Correspondence should be addressed to Allison Gates, agates@uwaterloo.ca

Received 16 November 2011; Accepted 26 December 2011

Academic Editors: K. McLeroy and A. Slep

Copyright (C) 2012 Allison Gates et al. This is an open access article distributed under the Creative Commons Attribution License, which permits unrestricted use, distribution, and reproduction in any medium, provided the original work is properly cited.

\begin{abstract}
Background. The current study established baseline nutrient intakes of youth and examined the potential for sustainability of a pilot school snack program in the remote First Nation of Kashechewan, Ontario, Canada. Methods. Twenty-four-hour dietary recalls established baseline intakes in grade 6-8 students $(n=43)$. Subsequently, a pilot healthy school snack program was initiated. Dietary recalls were completed one week $(n=43)$ and one year after the program $(n=67)$. Paired Wilcoxon signed-ranks tests were used to detect changes in intakes. Impressions of the teachers $(n=16)$, principal, and students were collected qualitatively. Results. Most youth had dietary intakes below current standards. Although vitamin $\mathrm{C}(P=0.024)$ and fibre $(P=0.015)$ intakes improved significantly after one week, these improvements were not sustained over the following year. Program impressions were positive. Conclusion. The need for a nutrition program is clear. While benefits were realized in the short term, improvements could not be maintained. Policy changes are needed to address barriers to sustainability.
\end{abstract}

\section{Introduction}

Widespread disparities in morbidity and mortality exist between Canadian Aboriginal (First Nations, Inuit, and Métis) and non-Aboriginal populations [1]. Canadian Aboriginal peoples often live in conditions and experience health outcomes comparable to those in developing nations [2]. In recent decades, obesity and type 2 diabetes have become epidemic in Aboriginal communities [3]. Data from the 2004 Canadian Community Health Survey (CCHS) indicated that the odds of obesity in Aboriginal people living off-reserve in Canada were more than two-and-a-half-times greater than in the general population [4]. Aboriginal children also experience higher rates of overweight and obesity compared to children of other ethnic backgrounds $[5,6]$. This is concerning, as childhood obesity is predictive of adult weight and morbidity, including hypertension, diabetes, and hypercholesterolemia [7-10].

Diet is an important contributor to obesity in Aboriginal populations [11], especially in geographically remote communities [12]. Research in Quebec, Canada, indicated that the diets of First Nation (FN) children contained little vegetables fruit, with the diet being energy dense [13]. A study of Native American youth also reported low consumption of vegetables and fruit, with the exception of potatoes and apples, and high intakes of foods high in fat, sugar, and salt [14]. Of importance, Canadian children who consumed vegetables and fruit, and fibre more frequently were less likely to be overweight or obese $[15,16]$.

The school is the ideal milieu for intervening in the diets of Aboriginal children, as they spend the majority of their time there during the week. While nutrition education 
TABLE 1: Dietary standards used in the analysis.

\begin{tabular}{|c|c|c|c|c|c|}
\hline \multirow{2}{*}{ Age group } & \multirow{2}{*}{ Nutrient or food group } & \multicolumn{2}{|c|}{ EAR, AI, or CFG standard ${ }^{\mathrm{a}}$} & \multicolumn{2}{|c|}{ CCHS mean intake ${ }^{\mathrm{b}}$} \\
\hline & & Male & Female & Male & Female \\
\hline \multirow{6}{*}{$9-13$ years } & Vegetables and fruit (servings) & 6 & 6 & 4.53 & 4.40 \\
\hline & “Other” foods (servings) & - & - & - & - \\
\hline & Fibre (g/day) & 31 & 26 & - & - \\
\hline & Folate ( $\mu \mathrm{g} /$ day) & 250 & 250 & - & - \\
\hline & Vitamin A (RAE/day) & 445 & 420 & - & - \\
\hline & Vitamin C (mg/day) & 39 & 39 & - & - \\
\hline \multirow{6}{*}{$14-18$ years } & Vegetables and fruit (servings) & 8 & 7 & 4.87 & 4.67 \\
\hline & “Other” foods (servings) & - & - & - & - \\
\hline & Fibre (g/day) & 38 & 26 & - & - \\
\hline & Folate ( $\mu \mathrm{g} /$ day $)$ & 330 & 330 & - & - \\
\hline & Vitamin A (RAE/day) & 630 & 485 & - & - \\
\hline & Vitamin C (mg/day) & 63 & 56 & - & - \\
\hline
\end{tabular}

"Other" foods are excluded as there is no formal recommendation or standard.

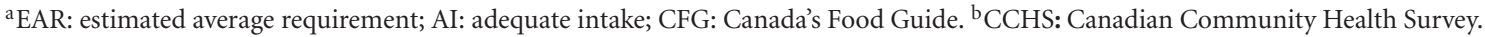

has been shown to improve knowledge about, exposure to and preferences for vegetables and fruit in remote FN communities, barriers still exist [17]. School food provision programs, however, may improve the diets of children living in remote, isolated communities by providing them with foods that would be otherwise inaccessible. This study established baseline nutrient intakes of youth in Kashechewan FN, Ontario, Canada, and examined the potential for the sustainability of a pilot school snack program, which was subsequently introduced.

\section{Materials and Methods}

2.1. Participants. Kashechewan is located on the Albany River, in the James Bay region of Ontario, Canada [18]. It is accessible only by air year-round, by barge during the ice-free months, and by winter road after freezeup. Similar to other remote FNs, living standards in Kashechewan are poor. There exists only one grocery store in the community.

2.2. Data Collection. The Waterloo Web-Based Eating Behaviour Questionnaire (WEB-Q) was used to establish baseline nutrient intakes of youth in grades 6-8, attending St. Andrew's School in Kashechewan, by assessing vegetable and fruit, and "other" foods consumption [19]. The WEB-Q incorporates a 24-hour dietary recall (including traditional foods) and a food frequency questionnaire [19]. The 24hour recall portion of the WEB-Q has good relative validity when compared to dietitian-administered interviews in FN students [19]. Data were collected in partnership with St. Andrew's School and with approval from the Office of Research Ethics at the University of Waterloo.

2.3. School Program. Subsequent to establishing baseline nutrient intakes, a pilot school snack program was initiated in May 2009. The program was supported by research funds and the ongoing program was sustained through a Breakfast for Learning (BFL) grant [20]. The program was planned in collaboration with community-based advisors. As the menu emphasized healthy items (e.g., vegetables and fruit) not available at the community store in type and/or quantity required for the intervention, food had to be ordered into the community. Investigators delivered the program for the first week after baseline was established. The program then continued under the direction of a trained volunteer coordinator, who was provided with detailed guidelines of what types of foods to serve, including a sample shopping list. Contact between the investigators and the program coordinator was maintained throughout the following year. The WEB-Q was used to collect nutrient data one week and one year after the program. The WEB-Q was also used to collect data on student impressions of the program at the end of the study; while, impressions of teachers and the school principal were gathered via a focus group facilitated by the investigators using a priori probes.

2.4. Data Analysis. Dietary data were analyzed in accordance with the 2007 Canadian Nutrient File (CNF) [21]. Analysis of food group servings was based on the 2007 version of Canada's Food Guide (CFG) [22]. Descriptive statistics for the sample were used to compare intakes to current standards, based on estimated average requirements (EARs) for folate, vitamin $\mathrm{A}$, and vitamin $\mathrm{C}$, adequate intakes (AIs) for fibre, and $\mathrm{CFG}$ recommendations for vegetables and fruit $[22,23]$. "Other" foods were defined according to CNF definitions, and included those foods that do not fit into any of the food groups of CFG, excluding unsaturated fats and oils, condiments, and water [21]. Mean vegetable and fruit intakes of students were also expressed in relation to mean intakes of Canadian children [24]. Standards and mean intakes used in the comparison are shown in Table 1.

Paired Wilcoxon signed-ranks tests were used for comparisons of dietary intakes at baseline to one week and one year after the program. Because nutrient intakes are influenced by total energy intake, nutrient and food group 
intakes were adjusted for energy intake using the nutrient density method, to reflect intakes per 1000 kilocalories (kcal) [25]. One-tailed analyses were used for the comparison of baseline to one week postprogram intakes, as an increase in vegetables and fruit, and related nutrient intake was predicted; a two-tailed analysis was used in the comparison of baseline to one year after the program, as no predictions were made due to the challenges of delivering a snack program in a remote community. Statistical significance was set at $P \leq$ 0.05. Qualitative data were collected via note taking by a trained research assistant and summarized.

\section{Results}

Characteristics of the study population for each time period are shown in Table 2. At all points, $100 \%$ of students present at school on the survey days completed the WEB-Q. Paired data were used to compare dietary intakes between baseline and one week (and one year) after the program (Table 3 ).

Following one week of the program, 64\% percent of students reported being motivated to eat healthier, and $67 \%$ reported making better choices about what they eat. Fortyeight and $81 \%$ of students reported eating more vegetables and fruit, respectively. Finally, $48 \%$ of students reportedly asked their parents to buy or serve the vegetables or fruit that they had tried at school.

\section{Discussion}

4.1. Dietary Intakes. Baseline dietary data (Table 3) clearly supported the need for the pilot program. At baseline, nearly all students had intakes of vegetables and fruit that fell below current recommendations (Table 4). Following one week of the program, significant increases in intakes of fibre and vitamin $\mathrm{C}$ were observed. However, nutrient and food group intakes were still less than current dietary standards and CFG recommendations for the majority of students, with the exception of vitamin C. Nevertheless, throughout the program, students were eager to try new foods. They expressed a desire to receive different vegetables and fruit. Students were very appreciative and overwhelmingly eager to try foods that they would otherwise never have the opportunity to taste. In the words of one student, "I'd never tasted kiwis before and cantaloupe. Thanks." Another simply stated, "I never knew cantaloupe tasted so good. We're glad you brought us snacks." Beyond introducing new foods, the program also provided the opportunity to improve students' attitudes and motivation to make healthy choices.

It is difficult for children and adolescents to concentrate and learn when they are hungry. Research has identified a positive relationship between breakfast and school attendance (and cognitive function) [26, 27]. During a focus group discussion, a number of teachers stressed the importance of the program, as most students did not eat breakfast regularly and would come to school hungry. Our WEB-Q data supported this assertion; at baseline, only $33 \%$ of students reported eating breakfast every day and $24 \%$ said that they never eat breakfast. As one student said, "I like having food in the morning because I am hungry." Another
TABLE 2: Characteristics of study population.

\begin{tabular}{lccc}
\hline & Baseline & $\begin{array}{c}\text { One week } \\
\text { after the } \\
\text { program }\end{array}$ & $\begin{array}{c}\text { One year after } \\
\text { the program }\end{array}$ \\
\hline$N^{\text {a }}$ & 43 & 43 & 67 \\
Age in years \pm SD & $13.1 \pm 0.9$ & $13.1 \pm 1.0$ & $13.5 \pm 1.1$ \\
\% males & 60.5 & 58.1 & 47.8 \\
\% females & 39.5 & 41.9 & 52.2 \\
\hline
\end{tabular}

a Based on all students who completed the questionnaire, not the matched samples.

student echoed this comment, expressing liking the program because, "it fills my stomach."

4.2. Challenges/Barriers. Challenges to the sustainability of this pilot program included the following. (1) The primary challenge was acquiring adequate funding. Although the one-week postprogram data were encouraging and a BFL grant was secured to fund the continuation of the program, this grant, like other similar funding opportunities, did not take into consideration the high cost of daily snack provision in a remote, northern location. Healthy foods were very expensive, typically 2-3 times as much as similar products in more southern, less isolated locations $[28,29]$. In the one community store, purchasing foods in bulk or at bulk prices was not possible, further stretching the limited available funds. Thus, the program coordinator was limited to what types of foods could be served and in what quantities. Consequently, the number of servings of vegetables and fruit provided declined from two servings per student in the first week, to one or less in the following year. (2) Inadequate facilities and storage space provided further challenges. Because the school consisted of portable classrooms, there was very little storage space and only one small refrigerator was available for storing perishable foods. There was also limited space for the preparation of food, including only one sink, which limited the types of foods that could be served due to food safety concerns [30]. Finally, the transportation of food from the point of preparation to the individual portables was a laborious process, especially when heavy foods (e.g., cantaloupe) were on the menu. (3) Another challenge was the inconsistent quality and availability of healthy foods. Kashechewan only has one grocery store; foods needed to be specifically ordered in advance so that they would be available in the quantities necessary for the program. However, because foods needed to be flown into the community, extenuating circumstances (e.g., storms, fresh produce freezing during transport) often meant that the planned foods would be unavailable or of unacceptable quality. It was commonplace that healthy foods needed to be replaced with less desirable alternatives (e.g., apples replaced with apple juice) because the healthier choice was no longer an option. (4) For the first year of the pilot, only one volunteer was available to coordinate the program. This meant that all responsibilities, including ordering, purchasing, preparing, and delivering the snacks fell on one individual. When the volunteer was forced to take a leave of 
TABLE 3: Comparison of changes indietary intakes from baseline ${ }^{a}$ (statistically significant values are shown in bold).

\begin{tabular}{|c|c|c|c|c|c|}
\hline \multirow{2}{*}{ Comparison } & \multirow{2}{*}{ Food group or nutrient } & \multicolumn{3}{|c|}{ Mean intakes \pm SD } & \multirow{2}{*}{$P$ value } \\
\hline & & Baseline & One week & One year & \\
\hline \multirow{6}{*}{$\begin{array}{l}\text { Baseline to one week } \\
\text { after the program } \\
(n=37)\end{array}$} & Vegetables and fruit (svgs) & $2.2 \pm 1.8$ & $2.7 \pm 2.0$ & - & 0.383 \\
\hline & “Other" foods (svgs) & $5.6 \pm 3.1$ & $6.6 \pm 4.9$ & - & 0.296 \\
\hline & Fibre (g/day) & $10.8 \pm 6.1$ & $13.9 \pm 8.3$ & - & 0.015 \\
\hline & Folate ( $\mu \mathrm{g} /$ day) & $247.6 \pm 145.8$ & $299.1 \pm 183.7$ & - & 0.430 \\
\hline & Vitamin A (RAE/day) & $307.8 \pm 243.9$ & $404.1 \pm 422.5$ & - & 0.271 \\
\hline & Vitamin C (mg/day) & $69.3 \pm 78.8$ & $126.7 \pm 114.8$ & - & 0.024 \\
\hline \multirow{6}{*}{$\begin{array}{l}\text { Baseline to one year } \\
\text { after the program } \\
(n=23)\end{array}$} & Vegetables and fruit (svgs) & $2.1 \pm 1.8$ & - & $1.1 \pm 1.0$ & 0.158 \\
\hline & “Other" foods (svgs) & $5.7 \pm 3.1$ & - & $3.9 \pm 2.7$ & 0.059 \\
\hline & Fibre (g/day) & $10.0 \pm 5.4$ & - & $8.0 \pm 4.5$ & 0.855 \\
\hline & Folate ( $\mu \mathrm{g} /$ day $)$ & $243.0 \pm 151.4$ & - & $193.4 \pm 156.1$ & 0.272 \\
\hline & Vitamin A (RAE/day) & $304.0 \pm 271.3$ & - & $197.9 \pm 222.6$ & 0.301 \\
\hline & Vitamin C (mg/day) & $55.7 \pm 74.5$ & - & $55.5 \pm 70.2$ & 1.000 \\
\hline
\end{tabular}

${ }^{a}$ Intakes shown in table are unadjusted; $P$ values of significance are for energy-adjusted intakes (per $\left.1000 \mathrm{kcal}\right)$.

TABLE 4: Dietary intakes compared to current recommendations.

\begin{tabular}{|c|c|c|c|}
\hline \multirow[b]{2}{*}{ Food group/nutrient } & \multicolumn{3}{|c|}{$\%<$ recommendation } \\
\hline & $\begin{array}{l}\text { Baseline } \\
(n=43)\end{array}$ & $\begin{array}{l}\text { One week after } \\
\text { the program } \\
(n=43)\end{array}$ & $\begin{array}{c}\text { One year after } \\
\text { the program } \\
\quad(n=67)\end{array}$ \\
\hline $\begin{array}{l}\text { Vegetables and fruit } \\
\text { (servings) }\end{array}$ & 95.3 & 90.7 & 98.5 \\
\hline Fibre $(\mathrm{g} / \text { day })^{\mathrm{a}}$ & 100.0 & 93.0 & 100.0 \\
\hline Folate ( $\mu \mathrm{g} /$ day $)$ & 55.8 & 51.2 & 68.7 \\
\hline $\begin{array}{l}\text { Vitamin A } \\
\text { (RAE/day) }\end{array}$ & 76.7 & 67.4 & 91.0 \\
\hline Vitamin C (mg/day) & 48.8 & 37.2 & 55.2 \\
\hline
\end{tabular}

${ }^{a}$ Recognizing that adequate intake is an estimation of adequacy and not a recommendation per se.

absence, no other volunteers were available to replace her, as teachers and teaching aids typically already had full schedules. When the program was reinitiated, for a short time it only ran twice per week, later returning to five days per week. Following one year of the program, the principal expressed concerns about insufficient personnel. He was, however, optimistic and expressed that with consistent funding, adequate resources, and dedicated volunteers the program could be very successful.

Together, these challenges/barriers contributed to the lack of improvement in dietary intakes from baseline to one year after the program (Table 3). Despite the lack of statistically significant impacts on dietary intakes, students generally remained excited about the program and feedback from teachers and the principal was overwhelmingly positive. The principal and teachers unanimously agreed that the program should continue into the future.

The improvements observed in attitudes and motivation to consume healthy foods are promising. Social cognitive theory recognizes that both attitudes and intentions (a consequence of motivation) are antecedent to behavior change
[31]. It must be recognized, however, that these act reciprocally with the environment [31]. Although many students in Kashechewan reported being motivated to eat healthier and asking their parents to buy the foods that were served at school, the nutrition environment in the greater community was not conducive to behavior change. As previously described, the availability and affordability of healthy foods in Kashechewan is less than ideal. The provision of healthy foods in school does not change the fact that the community food environment makes it extremely difficult, if not impossible, for many families to make healthy choices. This emphasizes the need for community-based interventions (e.g., cooperative buying groups, community gardens) to improve access to affordable, healthy foods in remote locations.

Lastly, data from the Northern Fruit and Vegetable Pilot Program, a nutrition education and food provision program piloted in 18 schools in the "near north" of Ontario, indicated that food provision combined with nutrition education resulted in a greater improvement in vegetable and fruit intakes as compared to food provision or nutrition education alone [32]. Thus, a more comprehensive program [33], including nutrition education, school food policy, family and community involvement, and food provision, to further target the vegetable and fruit intakes in this "far north" population is merited. This, however, would require policy changes resulting in significant resources in terms of funding, infrastructure, and staff, taking into account the unique environmental challenges of this region. The need for the program cannot be overstated; in the words of the principal, "the kids are always hungry." With adequate funding and resources, this program has the potential to positively impact the diet quality of children in Kashechewan.

\section{Acknowledgments}

The authors would like to thank the students of St. Andrew's School in Kashechewan for participating, and Kimberly Stephens, Bob Salvisburg, George Combden, Megan Chard, 
Alex Stephens, and Dr. Ian Martin for their help. This paper was funded by the Canadian Institutes of Health Research, Canada's Research-Based Pharmaceutical Companies Health Research Foundation (Rx\&D), Health Canada's First Nations and Inuit Health Branch, the Danone Institute of Canada, the Ontario Ministry of Research and Innovation, and the Heart and Stroke Foundation of Ontario.

\section{References}

[1] T. K. Young, "Review of research on aboriginal populations in Canada: relevance to their health needs," British Medical Journal, vol. 327, no. 7412, pp. 419-422, 2003.

[2] M. Cooke, D. Beavon, and M. McHardy, "Measuring the well-being of Aboriginal people: an application of the United Nations Human Development Index to Registered Indians in Canada, 1981-2001," in Indian and Northern Affairs Canada, 2004.

[3] T. K. Young, J. Reading, B. Elias, and J. D. O’Neil, “Type 2 diabetes mellitus in Canada's First Nations: status of an epidemic in progress," Canadian Medical Association Journal, vol. 163, no. 9, pp. 561-566, 2000.

[4] D. Garriguet, "Obesity and the eating habits of the Aboriginal population," Health Reports, vol. 19, no. 1, pp. 21-35, 2008.

[5] M. Story, J. Stevens, J. Himes et al., "Obesity in AmericanIndian children: prevalence, consequences, and prevention," Preventive Medicine, vol. 37, no. 1, pp. S3-S12, 2003.

[6] N. D. Willows, "Overweight in Aboriginal children: prevalence, implications and solutions," Journal of Aboriginal Health, vol. 2, pp. 76-85, 2005.

[7] W. H. Dietz, "Health consequences of obesity in youth: childhood predictors of adult disease," Pediatrics, vol. 101, no. 3, pp. 518-525, 1998.

[8] D. S. Freedman, L. K. Khan, W. H. Dietz, S. R. Srinivasan, and G. S. Berenson, "Relationship of childhood obesity to coronary heart disease risk factors in adulthood: the Bogalusa heart study," Pediatrics, vol. 108, no. 3, pp. 712-718, 2001.

[9] A. S. Singh, C. Mulder, J. W. R. Twisk, W. Van Mechelen, and M. J. M. Chinapaw, "Tracking of childhood overweight into adulthood: a systematic review of the literature," Obesity Reviews, vol. 9, no. 5, pp. 474-488, 2008.

[10] T. A. Nicklas, T. Baranowski, K. W. Cullen, and G. Berenson, "Eating patterns, dietary quality and obesity," Journal of the American College of Nutrition, vol. 20, no. 6, pp. 599-608, 2001.

[11] World Food Summit, "World Food Summit Plan of Action," 1996, http://www.fao.org/wfs/index_en.htm.

[12] K. Skinner, R. M. Hanning, and L. J. Tsuji, "Barriers and supports for healthy eating and physical activity for First Nation youths in northern Canada," International Journal of Circumpolar Health, vol. 65, no. 2, pp. 148-161, 2006.

[13] S. M. Downs, A. Arnold, D. Marshall, L. J. McCargar, K. D. Raine, and N. D. Willows, "Associations among the food environment, diet quality and weight status in Cree children in Québec," Public Health Nutrition, vol. 12, no. 9, pp. 15041511, 2009.

[14] J. Di Noia, S. P. Schinke, and I. R. Contento, "Dietary patterns of reservations and non-reservation Native American youths," Ethnicity and Disease, vol. 15, no. 4, pp. 705-712, 2005.

[15] A. J. G. Hanley, S. B. Harris, J. Gittelsohn, T. M. S. Wolever, B. Saksvig, and B. Zinman, "Overweight among children and adolescents in a Native Canadian community: prevalence and associated factors," American Journal of Clinical Nutrition, vol. 71, no. 3, pp. 693-700, 2000.
[16] M. Shields, "Nutrition: findings from the Canadian Community Health Survey-overweight Canadian children and adolescents," Statistics Canada, vol. 82-620-MWE, no. 1, pp. 2-34, 2005.

[17] A. Gates, R. M. Hanning, M. Gates, A. Isogai, J. Metatawabin, and L. J. S. Tsuji, "A school nutrition program improves vegetable and fruit knowledge, preferences, and exposure in First Nation youth," Nutrition Journal, vol. 5, pp. 1-6, 2011.

[18] Mushkegowuk Council, "Community Profiles," 2010, http:// www.mushkegowuk.ca/communityprofiles.html.

[19] R. M. Hanning, D. Royall, J. E. Toews, L. Blashill, J. Wegener, and P. Driezen, "Web-based food behaviour questionnaire: validation with grades six to eight students," Canadian Journal of Dietetic Practice and Research, vol. 70, no. 4, pp. 172-178, 2009.

[20] Breakfast for Learning, "Apply for a grant," 2011, http://www .breakfastforlearning.ca/en/services-a-information/apply-fora-grant.

[21] Health Canada, "Canadian Nutrient File," 2009, http://www .hc-sc.gc.ca/fn-an/nutrition/fiche-nutri-data/index-eng.php.

[22] Health Canada, "Eating Well with Canada's Food Guide-First Nations, Inuit and Métis," 2007, http://www.hc-sc.gc.ca/fnan/pubs/fnim-pnim/index-eng.php.

[23] Health Canada, "Dietary Reference Intakes Tables," 2006, http://www.hc-sc.gc.ca/fn-an/nutrition/reference/table/indexeng.php\#rvv.

[24] Statistics Canada, “Overview of Canadians' Eating Habits (Nutrition: findings from the Canadian Community Health Survey)," 2010, http://www.statcan.gc.ca/cgi-bin/af-fdr.cgi?l= eng\&loc=http://www.statcan.gc.ca/pub/82-620-m/82-620m2006002-eng.pdf\&t=Overview\%20of\%20Canadians'\%20 Eating\%20Habits\%20(Nutrition:\%20\%20Findings\%20from \%20the\%20Canadian\%20Community\%20Health\%20Survey).

[25] W. C. Willett, G. R. Howe, and L. H. Kushi, "Adjustment for total energy intake in epidemiologic studies," American Journal of Clinical Nutrition, vol. 65, no. 4, supplement, pp. 1220S1228S, 1997.

[26] A. Hoyland, L. Dye, and C. L. Lawton, "A systematic review of the effect of breakfast on the cognitive performance of children and adolescents," Nutrition Research Reviews, vol. 22, no. 2, pp. 220-243, 2009.

[27] G. C. Rampersaud, M. A. Pereira, B. L. Girard, J. Adams, and J. D. Metzl, "Breakfast habits, nutritional status, body weight, and academic performance in children and adolescents," Journal of the American Dietetic Association, vol. 105, no. 5, pp. 743-760, 2005.

[28] Aboriginal Affairs and Northern Development Canada, "Regional Results of Price Surveys," 2011, http://www.aincinac.gc.ca/nth/fon/fc/rgrs-eng.asp.

[29] L. J. S. Tsuji, "Mandatory use of non-toxic shotshell for harvesting of migratory game birds in Canada: cultural and economic concerns," Canadian Journal of Native Studies, vol. 18, pp. 19-36, 1998.

[30] Grey Bruce Health Unit, Kids Health Manual, 2011, http:// www.publichealthgreybruce.on.ca/.

[31] A. Bandura, "Health promotion by social cognitive means," Health Education and Behavior, vol. 31, no. 2, pp. 143-164, 2004.

[32] M. He, C. Beynon, M. Sangster Bouck et al., "Impact evaluation of the Northern Fruit and Vegetable Pilot Programme-a cluster-randomised controlled trial," Public Health Nutrition, vol. 12, no. 11, pp. 2199-2208, 2009.

[33] Centers for Disease Control and Prevention, "Guidelines for school health programs to promote lifelong healthy eating. Centers for Disease Control and Prevention," MMWR Surveillance Summaries, vol. 45, no. 9, pp. 1-42, 1996. 


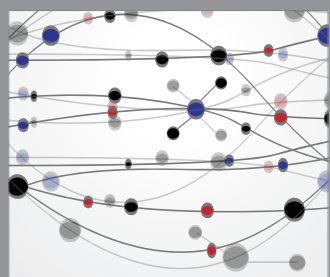

The Scientific World Journal
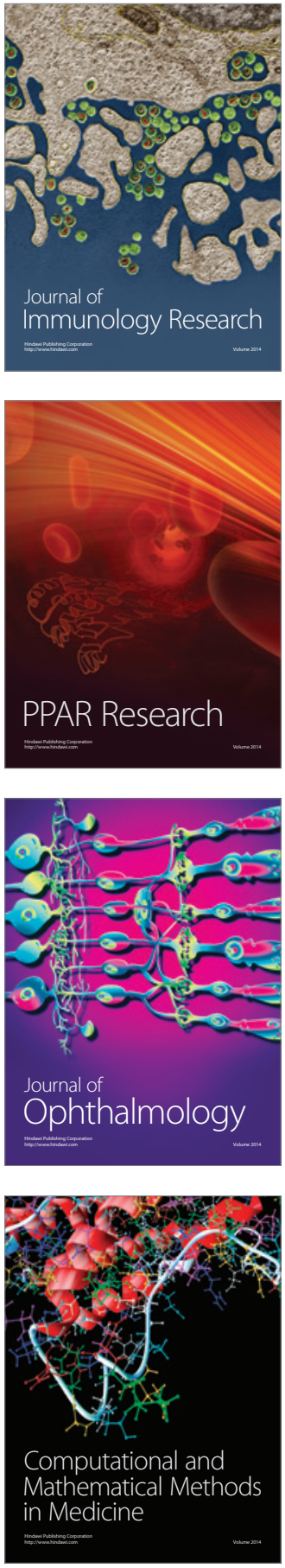

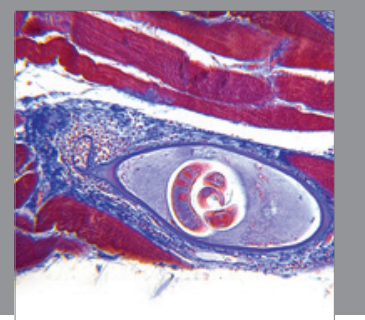

Gastroenterology

Research and Practice
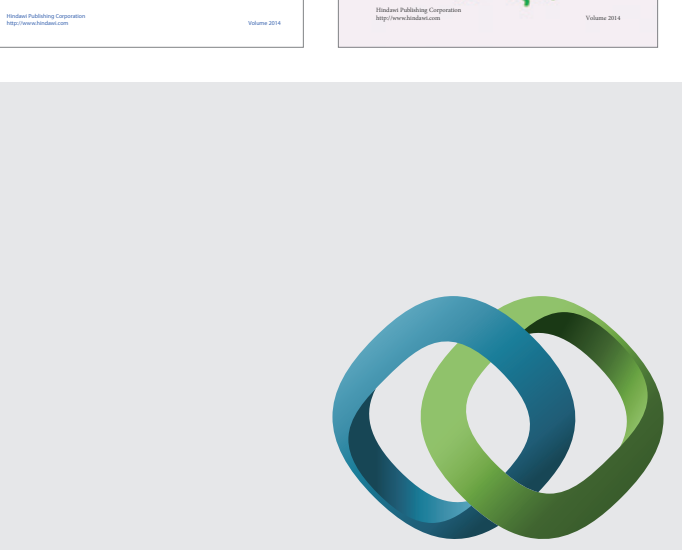

\section{Hindawi}

Submit your manuscripts at

http://www.hindawi.com


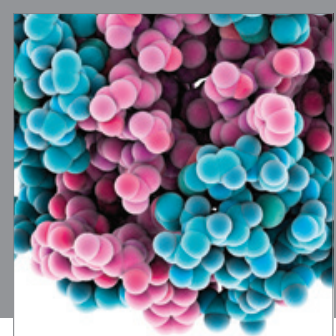

Journal of
Diabetes Research

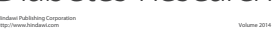

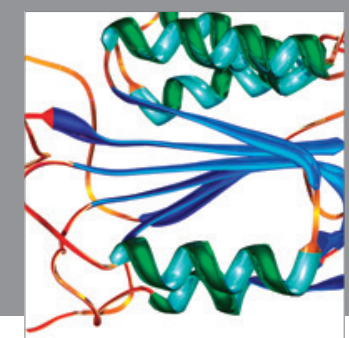

Disease Markers
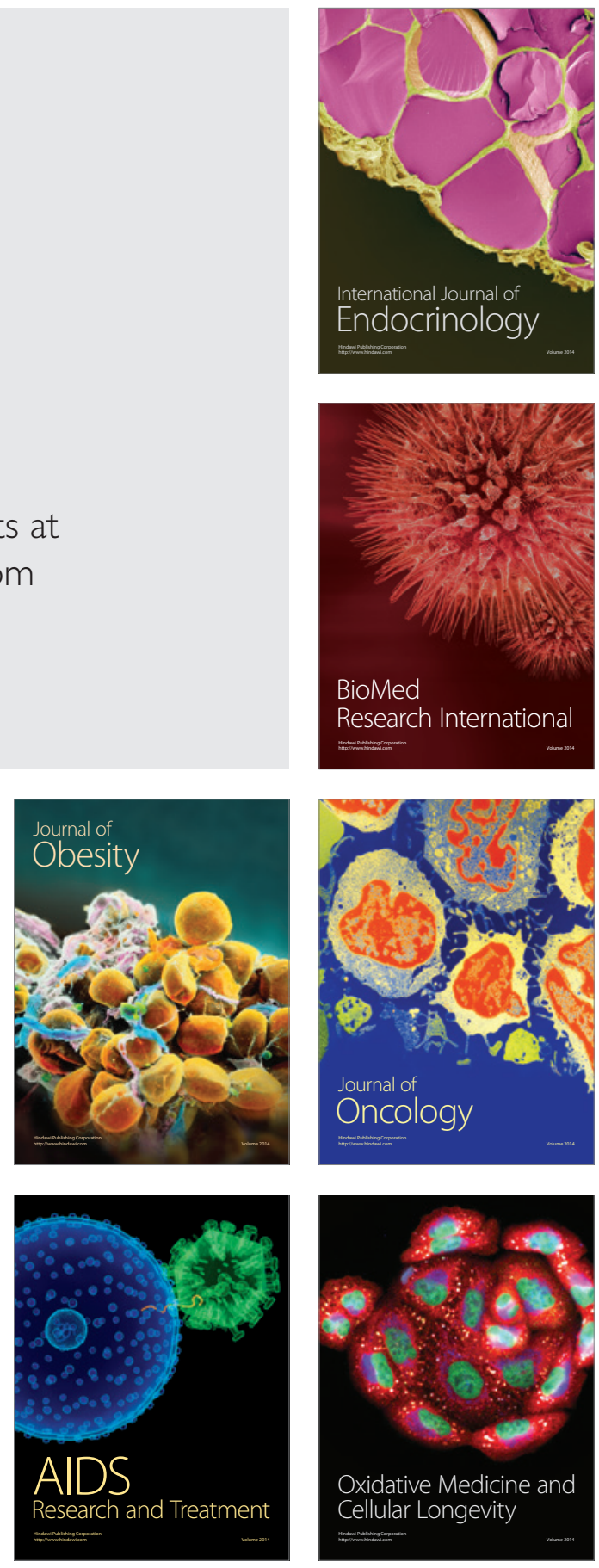